\title{
IMPLICAÇÕES DA VULNERABILIDADE AMBIENTAL NA QUALIDADE DAS ÁGUAS SUPERFICIAIS DA BACIA DO CÓRREGO DAS ANTAS, TUPI PAULISTA/SP
}

Rafael Brugnolli Medeiros ${ }^{1}$

André Luiz Pinto ${ }^{2}$

\section{Angélica Estigarribia São Miguel $^{3}$}

RESUMO: O cenário atual dos recursos hídricos aponta que além da escassez da água e a redução de sua qualidade exercem grande pressão sobre a qualidade de vida das comunidades aquáticas e humanas. Por isto esta pesquisa objetivou analisar a influência da vulnerabilidade ambiental, considerando os parâmetros geologia, solos, declividade, uso e ocupação, clima, na qualidade e enquadramento das águas superficiais da bacia do córrego das Antas, localizada no município de Tupi Paulista/SP. Para isso utilizou-se a metodologia de Ross (1994) e Crepani et. al. (2001), baseada em 5 categorias hierárquicas de grau de vulnerabilidade, desde Muito Fraco até Muito Forte, para posteriormente analisar a influência deste fator na qualidade das águas através de parâmetros como o oxigênio dissolvido, $\mathrm{pH}$, turbidez, condutividade elétrica e temperaturas do ar e água monitoradas na estação de inverno de 2013 em 6 pontos ao longo do canal principal, qualificando conforme resolução 357 de 2005 do CONAMA. Percebe-se que a bacia obteve como maior área, a vulnerabilidade média e foi notado que todas as características físicas apresentadas alteram a qualidade dos recursos hídricos, enquadrando assim a bacia na classe II de qualidade.

Palavras-chave: Qualidade das águas. Vulnerabilidade ambiental. Recursos hídricos.

\footnotetext{
${ }^{1}$ Acadêmico em Geografia Bacharelado da UFMS/CPTL. e-mail: rafael bmedeiros@hotmail.com;

${ }^{2}$ Prof. Dr. Associado III da UFMS/CPTL. e-mail: andre.pinto@ufms.br;

${ }^{3}$ Acadêmica em Geografia Bacharelado da UFMS/CPTL. e-mail: angelica.esm@hotmail.com.
} 


\section{INTRODUÇÃO}

O monitoramento dos parâmetros de qualidade das águas vem sendo aplicado para diagnosticar os principais impactos negativos no meio ambiente e a relação destes com as atividades antrópicas desenvolvidas em uma bacia hidrográfica. Para uma melhor compreensão desta dinâmica delimita-se o estudo em bacias hidrográficas onde são observados as inter-relações dos usos múltiplos e os recursos naturais.

Christofoletti (1980) caracteriza a Bacia Hidrográfica como uma área limitada por divisores de água, detro da qual são drenados os recursos hidricos, através de um curso de água, como um rio e seus afluentes. A área física, assim delimitada, constitui-se em importante unidade de planejamento.

Para a análise e entendimento de como o uso de um recurso natural influência na qualidade das águas, é necessário um diagnóstico de todas as caracaterísticas físicas da bacia, elaborando assim a vulnerabilidade do ambiente perante aos processos erosivos, que podem influência de forma direta a qualidade e quantidade dos recursos hídricos.

Para Lima et al. (2000), a vulnerabilidade de um geossistema é avaliada analisando-se características dos meios físicos (solo, rocha, relevo, clima e recursos hídricos), e antrópico (uso e ocupação do solo), que tornam o relevo mais ou menos instável ou sujeito a processos erosivos.

Visando a melhora no ordenamento da bacia, a Companhia Energética de São Paulo (CESP) está realizando nesta área o replantio da mata ciliar para promover entre outros fatores, uma melhora na qualidade e quantidade dos recursos hídricos, por isto, se iniciou pesquisas a fim de elaborar as influências deste replantio e das características físicas da bacia sobre os recursos hídricos.

O termo água refere-se, de modo geral ao elemento químico natural, desvinculado de qualquer uso ou utilização. Por sua vez, o termo recurso hídrico é a consideração da água como bem econômico, passível de utilização com tal fim. Entretanto, deve-se ressaltar que toda água não é, necessariamente, um recurso hídrico, na medida em que seu uso ou utilização nem sempre tem viabilidade econômica (REBOUÇAS, 2002).

Apesar dos recursos superficiais serem abundantes, sua captação e o suprimento essencial para o consumo humano, ao desenvolvimento das atividades industriais, 
agrícolas e à sobrevivência dos ecossistemas continentais, está sendo cada vez mais limitado por fatores econômicos e condições de poluição prejudicando a população de usufruir desse bem e tornando mais custoso o tratamento de água (PINTO, 1998)

$O$ presente trabalho tem como objetivo avaliar a influencia da vulnerabilidade ambiental da bacia do córrego das Antas, considerando os parâmetros da geologia, solos, declividade, uso da terra e clima do local, na qualidade e enquadramento de suas águas superficiais, utilizando-se da metodologia proposta por Ross (1994) e Crepani et al. (2001) e do auxilio da ferramenta ArcGis $10^{\circledast}$. Visando subsidiar o uso, ocupação e manejo da terra sustentável da bacia, com a redução da perda de solos, produtividade, quantidade e qualidade das suas águas superficiais e consecutivamente melhorando a qualidade de vida de seus moradores e usuários de seus produtos agropecuários e hortifrutigranjeiros.

A bacia do córrego das Antas, localiza-se no município de Tupi Paulista/SP, entre as coordenadas de $21^{\circ} 23^{\prime} 50^{\prime \prime}$ e $21^{\circ} 26^{\prime} 40^{\prime \prime}$ de latitude $S$ e $51^{\circ} 35^{\prime} 00^{\prime \prime}$ e $51^{\circ} 31^{\prime} 40^{\prime \prime}$ de longitude W (Figura 1).
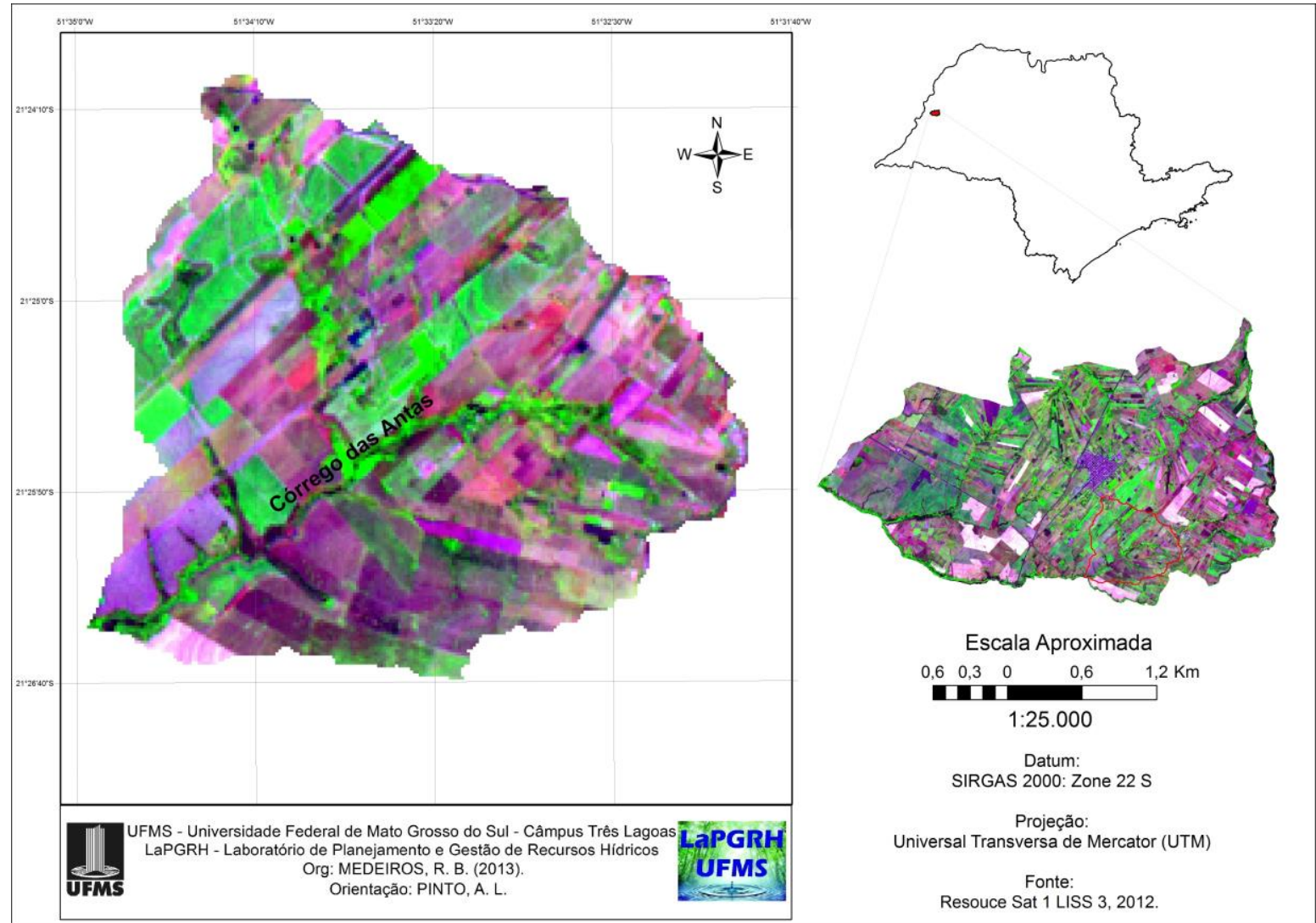

Figura 1: Mapa de Localização e Articulação da Bacia do Córrego Moeda, Três Lagoas/MS. 


\section{DESENVOLVIMENTO}

\subsection{METODOLOGIA}

Para obtenção do mapa de vulnerabilidade ambiental, utilizou-se a metodologia proposta por Ross (1994) e Crepani et al. (2001), através do levantamento dos dados necessários sobre a bacia do córrego Moeda para posteriormente ser atribuídos pesos para cada característica física, (1 - Muito Fraco; 2 - Fraco; 3 - Médio; 4 - Forte; 5 - Muito Forte), sendo desenvolvida com base no conceito de ecodinâmica de Tricart (1977) onde propôs que a paisagem fosse estudada pelo seu comportamento dinâmico, ou seja, a partir do entendimento das relações mútuas entre os diversos componentes do sistema e dos fluxos de energia e matéria no ambiente.

O mapa de vulnerabilidade abrange as variáveis de geologia, solos, declividade, uso da terra e clima, para posteriormente elaborar a influencia na qualidade das águas da bacia do córrego das Antas.

A caracterização geológica da área de estudo foi elaborada com o auxílio do ArcGis $10^{\circledR}$, onde na extensão ArcMap 10, gerou-se o mapa geológico do estado de São Paulo na escala de 1:750.000, dados técnicos do Serviço Geológico do Brasil (CPRM). A partir dos dados recortou a área da bacia, calculando-se a área em $\mathrm{km}^{2}$ que cada disposição geológica ocupa.

A carta de solos da área de estudo foi elaborado com o auxílio do $\operatorname{ArcGis}^{\circledR} 10$, no mesmo procedimento descrito no item anterior, utilizando os dados técnicos da EMBRAPA (1999), que foram adicionados ao $\operatorname{ArcGis}^{\circledR}$, onde o mesmo descreve a disposição dos solos pelas siglas, onde foi nomeado de acordo com a nova nomenclatura da (EMBRAPA 2006) finalizando assim a carta de solos.

A declividade da bacia foi obtida através dos dados altimétricos da imagem SRTM, com o auxílio da ferramenta Spatial Analyst, em seguida a opção Surface e Slope, sendo que pode ser escolhido declive em graus e/ou porcentagem, neste caso foi gerada pela porcentagem.

A elaboração da carta de declividade é uma ferramenta importante para a análise da qualidade ambiental, pois como Oliveira et al., (2007) afirma, o grau de declive do terreno exerce influência direta sobre a quantidade de perda de solo por erosão, pois, 
quanto maior sua gradiente, maior a intensidade de escoamento das águas sob o efeito da gravidade, sendo, menor o seu tempo disponível para a infiltração no solo.

Para a elaboração do uso e ocupação da terra foi feita uma interpretação de imagens de satélite Resource Sat 1 LISS 3, bandas 3,4 e 5 do ano de 2012 adquiridas gratuitamente no site do INPE - Instituto Nacional de Pesquisas Espaciais, para a delimitação da bacia utilizou a imagem de radar SRTM (Shuttle Radar Topography Mission) do ano de 2000.

$\mathrm{Na}$ classificação foram definidas classes temáticas usando as cores conforme IBGE (2006). A definição das classes do uso e ocupação da terra do ano de 2012 foi dividida em: Classe florestal é referente às áreas de reserva legal, matas ciliares e florestas plantadas. Na classe temática água foi classificada todos os corpos d'água. Os solos sem cobertura vegetal ou aquelas terras que estão sendo preparadas para plantio, foram classificados como solo nu. As classes lavoura temporária referem-se às áreas de cultivo temporário, hortas, mandioca, etc. Na classe silvicultura, foi adquiridas amostras de plantio de eucalipto. Já a classe temática pastagem foi caracterizada pela presença de gramíneas destinadas ou não para a criação do gado de corte. A classe lavoura permanente foi destinada para cultivo de café, laranja, coco, etc. As áreas diversas são locais de casas das fazendas, galpões, etc. A cana de açúcar como próprio nome diz, são áreas destinadas ao plantio da mesma e por fim a classe de solo úmido são áreas de várzeas ou pontos de alagamentos.

Por fim a imagem classificada foi importada no $\operatorname{ArcGis}^{\circledR} 10$, para corrigir os erros que no Spring ${ }^{\circledR}$ não foi possível, analisando cada região e mudando aquelas que apresentavam erros, alterando assim seu atributo de acordo com a realidade mostrada na imagem de satélite.

$\mathrm{Na}$ elaboração da carta de pluviosidade, se utilizou dos dados de 4 estações meteorológicas próximas a bacia do córrego das Antas, como mostra a (Tabela 1), sendo utilizado a média anual de cada estação, para posteriormente através da interpolação de dados feita pelo ArcGis 10, elaborar a carta com a média de precipitação em cada ponto da bacia, foram analisadas as médias de cidades próximas à bacia, através do site da EMBRAPA, pois a própria cidade de Tupi Paulista não foi encontrado a média de precipitação. 


\section{Then Fórum Ambiental \\ da Alta Paulista \\ ISSN 1980-0827 \\ Volume 9, Número 2, 2013 \\ Bacias Hidrográficas, Planejamento e

Esta carta é importante nesta análise, pois o clima exerce influência direta na vulnerabilidade, pois controla os processos erosivos diretamente, através da precipitação pluviométrica e da temperatura de uma região, e também indiretamente através dos tipos de vegetação que poderão cobrir a paisagem" (CREPANI et al., 2001.p.94), além de alterar os processos erosivos, atuam diretamente na qualidade da água, pois o escoamento superficial e o próprio processo erosivo, altera sua qualidade, reduzindo sua disponibilidade.

Tabela 1: Coordenadas Geográficas e Precipitação Anual, próximas da bacia do Córrego das Antas.

\begin{tabular}{c|c|c}
\hline Município & Coordenadas Geográficas & Precipitação (mm) \\
\hline Dracena & $21^{\circ} 28^{\prime} 22^{\prime \prime S} ; 51^{\circ} 31^{\prime} 31^{\prime \prime} \mathrm{W}$ & 1.193 \\
\hline Monte Castelo & $21^{\circ} 18^{\prime} 0 " \mathrm{~S} ; 51^{\circ} 33^{\prime} 36 \mathrm{~W}$ & 1.021 \\
\hline Panorama & $21^{\circ} 21^{\prime} 0 " \mathrm{~S} ; 51^{\circ} 51^{\prime} \mathrm{O}^{\mathrm{W}} \mathrm{W}$ & 1.102 \\
\hline Irapuru & $21^{\circ} 34^{\prime} 12 " \mathrm{~S} ; 51^{\circ} 21^{\prime} 11 \mathrm{~W} \mathrm{~W}$ & 1.217 \\
\hline
\end{tabular}

Fonte: EMBRAPA.

Org: MEDEIROS, 2013.

Todos estes parâmetros são de extrema importância na análise ambiental, como também pode-se notar, a relevância da influência destes fatores, na qualidade e enquadramento das águas superficiais da bacia do córrego das Antas.

Para a análise dos parâmetros para a mensuração da qualidade das águas superficiais do Córrego das Antas, foi utilizado o Horiba U-50 Series Multiparameter water Quality Unit's para a medição e geração dos parâmetros aferidos no campo. Cada parâmetro tem sua importância na análise da qualidade da água, estas variáveis são, Oxigênio Dissolvido (OD), pH, Temperatura do ar e da água, condutividade elétrica, turbidez e diversos outros fatores, mas para essa análise vão ser utilizados estes já citados.

O oxigênio dissolvido o elemento principal no metabolismo dos microrganismos aeróbios que habitam as águas naturais ou os reatores para tratamento biológico de esgotos. Nas águas naturais, o oxigênio é indispensável também para outros seres vivos, especialmente os peixes, onde a maioria das espécies não resiste a concentrações de oxigênio dissolvido na água inferiores a 4,0 mg/L. É, portanto, um parâmetro de extrema relevância na legislação de classificação das águas naturais, bem como na composição de índices de qualidade de águas (IQAs). No IQA utilizado no Estado de São Paulo pela 
CETESB, a concentração de oxigênio dissolvido é um parâmetro que recebe uma das maiores ponderações.

A condutividade expressa à capacidade de condução de corrente elétrica de sais dissolvidos e ionizados presentes numa água, pode ser utilizada como parâmetro de avaliação de qualidade, segundo Matheus et. al. (1995).

A turbidez é a alteração da penetração da luz provocada por partículas em suspensão, como bactérias, argilas e silte ou fontes de poluição que lançam materiais finos e outras substâncias na água. A presença dessas substâncias provoca a dispersão e a absorção da luz, dando à água aparência nebulosa, esteticamente indesejável e potencialmente perigosa (PINTO, 1998). Com concentrações recomendadas pelo CONAMA Resolução 357/05, classe I, até 40 unidades nefelométrica de turbidez NTU.

$\mathrm{O} \mathrm{pH}$ apresenta a acidez ou a basicidade das águas, que podem ter origens em fatores naturais do terreno ou resultantes de poluentes dissolvidos na água. Para analise será utilizado os limites da Resolução CONAMA 357, de 17/03/05, que se estende de 6,0 a 9,0 .

A temperatura do ar e da água influencia nos processos biológicos, reações químicas e bioquímicas que ocorrem na água e também outros processos como solubilidade dos gases dissolvidos, além de acentuar a sensação de sabor e odor (PINTO, 1998).

A (Tabela 2) e (Quadro 1) apresentam a legislação do Conselho Nacional do Meio Ambiente (CONAMA), quais são os principais parâmetros usados no enquadramento de qualidade para águas superficiais e o enquadramento de uso das mesmas, foi utilizada apenas a resolução 357 de 2005.

Tabela 02: Limites dos Parâmetros Analisados para Enquadramento nas Classes das Águas Doces no Brasil.

\begin{tabular}{l|l}
\hline Classes & Limites para o Enquadramento \\
\hline \multirow{3}{*}{ Especial } & Nas águas de classe especial deverão ser mantidas as condições naturais \\
do corpo de água. & OD $+10,0 \mathrm{mg} / \mathrm{l}$ \\
& pH 6,0 a 9,0 \\
Turbidez até $20 \mathrm{NTU}$ \\
Condutividade Elétrica até 50 um \\
\hline
\end{tabular}




\begin{tabular}{l|l}
\hline II & $\begin{array}{l}\text { OD } 6 \text { a } 5 \mathrm{mg} / \mathrm{l} \\
\text { pH } 6,0 \text { a } 9,0 \\
\text { Turbidez } 40 \text { até } 70 \text { NTU } \\
\text { Condutividade Elétrica } 75 \text { até } 100 \mathrm{um}\end{array}$ \\
\hline III & $\begin{array}{l}\text { OD } 5 \text { a } 4 \mathrm{mg} / \mathrm{l} \\
\text { pH } 6,0 \text { a } 9,0 \\
\text { Turbidez } 70 \text { até } 100 \mathrm{NTU} \\
\text { Condutividade Elétrica } 100 \text { até } 150 \mathrm{um}\end{array}$ \\
\hline IV & $\begin{array}{l}\text { OD } 4 \mathrm{mg} / \mathrm{l} \\
\text { pH } 6,0 \text { a } 9,0 \\
\text { Turbidez acima de } 100 \text { NTU } \\
\text { Condutividade Elétrica }+150 \text { um }\end{array}$ \\
\hline
\end{tabular}

Fonte: Resolução n. 357 do CONAMA de 17/03/2005 adaptado por Pinto et. al. (2010).

Quadro 1: Principais Classes de Limitações de Uso das Águas Doces no Brasil.

\begin{tabular}{|c|l|}
\hline Classes & Principais Usos \\
\hline Especial & $\begin{array}{l}\text { Consumo humano com desinfecção; Preservação de equilíbrio natural das } \\
\text { comunidades aquáticas; Preservaça dos ambientes aquáticos em unidades de } \\
\text { conservação de proteção integral. }\end{array}$ \\
\hline | & $\begin{array}{l}\text { Consumo humano, após tratamento simplificado; Proteção das comunidades } \\
\text { aquáticas; Recreação de contato primário (natação, esqui aquático e mergulho) } \\
\text { Resolução CONAMA n. 274, de 2000; Irrigação de hortaliças que são consumidas } \\
\text { cruas e de frutas que se desenvolvam rentes ao solo e que sejam ingeridas sem } \\
\text { remoção de películas e à proteção das comunidades aquáticas em Terras } \\
\text { Indígenas. }\end{array}$ \\
\hline II & $\begin{array}{l}\text { Abastecimento para consumo humano, após tratamento convencional, à proteção } \\
\text { das comunidades aquáticas, à recreação de contato primário, tais como natação, } \\
\text { esqui aquático e mergulho, Resolução conAMA n. 274, de 2000, à irrigação de } \\
\text { hortaliças, plantas frutíferas e de parques, jardins, campos de esporte e lazer, com } \\
\text { os quais o público possa vir a ter contato direto e à aqüicultura e à atividade de } \\
\text { pesca. }\end{array}$ \\
\hline III & $\begin{array}{l}\text { Abastecimento para consumo humano, após tratamento convencional ou avançado, } \\
\text { à irrigação de culturas arbóreas, cerealíferas e forrageiras, à pesca amadora, à } \\
\text { recreação de contato secundário e à dessedentação de animais. }\end{array}$ \\
\hline IV & \begin{tabular}{l} 
Navegação e à harmonia paisagística \\
\hline
\end{tabular}
\end{tabular}

Fonte: Resolução №. 357 do CONAMA de 17/03/2005.

Os locais da coleta foram enumerados do primeiro ponto até o ponto 6 . Os pontos foram escolhidos previamente segundo critérios como: áreas de replantios de mudas para a recomposição da mata ciliar pela CESP (Companhia de Energia de São Paulo), em locais próximos de pastagens ou com declive mais acentuado, podendo assim analisar a influencia destes fatores na qualidade das águas superficiais do córrego das Antas.

\subsection{RESULTADOS}


A bacia do córrego das Antas assentasse sobre terrenos do grupo Bauru, que engloba as Formações Santo Anastácio é constituída por arenitos, compostos por sedimentos com maior contribuição de areia fina a silte grosso (Sallun et al., 2010).

A Formação Vale do Rio do Peixe é composta por camadas de espessura submétrica, estruturação tabular típica, de arenitos intercalados com siltitos ou lamitos arenosos. Os arenitos são muito finos a finos, marrom-claro rosado a alaranjado, de seleção moderada a boa. Têm aspecto maciço ou estratificação cruzada tabular e acanalada de médio a pequeno porte. Nos estratos "maciços", podem ocorrer zonas de estratificação/laminação plano-paralela grosseira, formadas por: a) superfícies onduladas (amplitude e comprimento de onda centimétricos), às vezes com laminação interna (climbings eólicos); b) ondulações de adesão; ou c) planos bem definidos, com lineação de partição, (Fernandes et. al.; 2003). A (Tabela 3) mostra a disposição geológica da bacia do córrego das Antas, apontando que grande parte de sua área se encontra na Formação Vale do Rio do Peixe, apenas no baixo curso, próximo da foz do córrego das Antas, que foi constatada a Formação Santo Anastácio.

Tabela 3: Geologia e seus respectivos pesos da Bacia do Córrego das Antas, Tupi Paulista/SP.

\begin{tabular}{c|c|c|c|c}
\hline Estratigrafia & Disposição Geológica & $\begin{array}{c}\text { Área } \\
\left(\mathbf{K m}^{2}\right)\end{array}$ & Área (\%) & $\begin{array}{c}\text { Pesos de } \\
\text { Vulnerabilidade }\end{array}$ \\
\hline \multirow{2}{*}{ Grupo Bauru } & Formação Vale do Rio do Peixe & 17,34 & 93,23 & $\mathbf{5}$ \\
\cline { 2 - 5 } & Formação Santo Anastácio & 1,26 & 6,77 & $\mathbf{2}$ \\
\hline & TOTAL & 18,60 & 100,00 & \\
\hline
\end{tabular}

Org: MEDEIROS (2013).

Orientação: PINTO, A. L.

Com relação aos solos, na bacia foi encontrado apenas o solo Argissolo Vermelho/Amarelo que é mineral, que tem como características diferenciais a presença do horizonte $B$ textural de argila de atividade baixa ou alta conjugada por bases baixa ou caráter alitico. (EMBRAPA, 2006), assim sendo toda a bacia nesta questão, foi classificada como peso 2 de vulnerabilidade ambiental de acordo com Ross (1994).

Outra variável que altera a qualidade das águas e possui uma variável importante na vulnerabilidade ambiental, é a declividade (Tabela 4) foi feita a partir da metodologia de Lepsch (2002) e Ross (1994), que indicou declividade até 15,64\%, chegando ao peso 3 de vulnerabilidade. 
Tabela 4: Classes de Declividade na Bacia do Córrego das Antas, Tupi Paulista/SP.

\begin{tabular}{c|c|c|c}
\hline Pesos de Vulnerabilidade & Declividade (\%) & Área $\left(\mathbf{K m}^{2}\right)$ & Área $(\%)$ \\
\hline $\mathbf{1}$ & $0-6,00$ & 14,47 & 77,79 \\
\hline 3 & $6-12,00$ & 3,58 & 19,26 \\
\hline & $12-15,64$ & 0,55 & 2,95 \\
\hline & TOTAL & 18,60 & 100,00 \\
\hline
\end{tabular}

Org: MEDEIROS (2013).

Orientação: PINTO, A. L.

A classe de declive de $0-6 \%$ se apresentou em grande parte da bacia, sendo classificada como peso 1 de vulnerabilidade e abrangeu com $77,79 \%$ de toda a área, sendo que de $0-3 \%$ de declive é considerada uma área apta a qualquer uso agrícola e de $3 \%$ a $6 \%$ são áreas com nenhuma ou somente pequenas limitações de uso, são indicadas para o plantio de culturas anuais, com o uso de práticas simples de conservação do solo, segundo Lepsch et. al. (2002). A classe de $6-12 \%$ foi localizada em pontos isolados da, abrangendo $19,26 \%$ de toda a área e classificada como peso 2 , por fim, a classe 12 a 15,64\% foi encontrada em poucos pontos na bacia, apontando apenas $2,95 \%$ da área, por ser uma área com declive mais acentuado, foi classificada como peso 3 de vulnerabilidade ambiental.

Com relação ao uso do solo, o mesmo tem influencia direta na vulnerabilidade pois alteram significativamente a qualidade ambiental, dependendo do seu manejo e da forma como vem sendo utilizado este solo.

A (Tabela 5) apresenta a forma como vem sendo utilizado o uso da terra na bacia do córrego das Antas em 2012. Assim, percebe-se que a pastagem se mostra predominante na bacia, com $52,47 \%$ da área total, outro uso bem predominante na bacia, é a cana de açúcar, que abrangeu 19,52\% da área.

Sendo esta bacia muito diversificada, onde foi notadas plantações de laranja, café, coco, essas, classificadas como lavoura permanente e abrange 5,75\%, já áreas de hortas, plantações de pepino, mandioca foram enquadradas como lavoura temporária que ocupou $4,03 \%$ da área da bacia.

As áreas destinadas à classe florestal, onde abrangeu as mata ciliares existentes e os locais em fase de recomposição pela CESP, além das reservas legais, abrangeram $6,34 \%$ da bacia. Foram constatadas algumas áreas de solo nu, preparadas para cultivo, ocupou $3,49 \%$. 
Tabela 5: Classes de Uso e Ocupação da Terra e Vulnerabilidade na Bacia do Córrego das Antas, Tupi Paulista/SP, em 2012.

\begin{tabular}{c|c|c|c}
\hline $\begin{array}{c}\text { Pesos de } \\
\text { Vulnerabilidade }\end{array}$ & Uso do Solo & Área $\left.\mathbf{K m}^{2}\right)$ & Área (\%) \\
\hline $\mathbf{2}$ & Florestal & 1,18 & 6,34 \\
\hline $\mathbf{3}$ & Cana de Açúcar & 3,63 & 19,52 \\
\hline $\mathbf{3}$ & Pastagem & 9,76 & 52,47 \\
\hline $\mathbf{3}$ & Silvicultura & 0,75 & 4,03 \\
\hline $\mathbf{3}$ & Lavoura Permanente & 1,07 & 5,75 \\
\hline $\mathbf{4}$ & Lavoura Temporária & 0,75 & 4,03 \\
\hline $\mathbf{4}$ & Solo Úmido & 0,40 & 2,15 \\
\hline 5 & Hidrografia & 0,23 & 1,24 \\
\hline 5 & Áreas Diversas & 0,18 & 0,97 \\
\hline 5 & Solo nu & 0,65 & 3,49 \\
\hline & TOTAL & 18,60 & 100,00 \\
\hline
\end{tabular}

Org: MEDEIROS (2013).

Orientação: PINTO, A. L.

De acordo com a metodologia utilizada, percebe-se que os parâmetros referentes ao clima ocorrem homogeneamente em toda a área de estudo, sendo classificada como Peso 2, que são áreas de fraca vulnerabilidade, de acordo com CREPANI, et. al. (2001).

Os cinco dados (Geologia, Solos, Declividade, Uso do Solo e Clima), basearam-se na metodologia do Ross (1994) e Crepani et. al. (2001) na qual todos os Pl's possuem pesos iguais. Sendo importante recordar que os valores mais próximos a 1 (um) são áreas menos susceptíveis a erosão e os valores mais próximos a 5 (cinco) são áreas com maior potencial erosivo. Esses dados são de extrema importância na obtenção da carta de vulnerabilidade ambiental que por sua vez influenciam de forma direta na qualidade dos recursos hídricos da bacia.

A vulnerabilidade ambiental da bacia, representada pelas (Tabela 6) e (Figura 2), foi cruzada com os dados de qualidade e enquadramento das águas superficiais do córrego (Tabela 7), possibilitando avaliar a influência da vulnerabilidade, nos trechos monitorados a qualidade das águas da bacia e onde eles exercem maiores influência.

Tabela 6: Vulnerabilidade Ambiental e suas Respectivas Áreas em $\left(\mathrm{km}^{2}\right)$ e (\%).

\begin{tabular}{c|c|c|c}
\hline Pesos & Categoria Hierárquica & Área $\left(\mathbf{k m}^{2}\right)$ & Área (\%) \\
\hline $\mathbf{1}$ & Muito Fraca & 0,00 & 0,00 \\
\hline $\mathbf{2}$ & Fraca & 5,46 & 29,35 \\
\hline $\mathbf{3}$ & Média & 7,33 & 39,41 \\
$\mathbf{4}$ & Forte & 5,16 & 27,64 \\
\hline $\mathbf{5}$ & Muito Forte & 0,65 & 3,60 \\
\hline
\end{tabular}




\begin{tabular}{r|r|r}
\hline TOTAL & 18,60 & 100,00 \\
\hline Org: MEDEIROS (2013).
\end{tabular}

Orientação: PINTO, A. L.

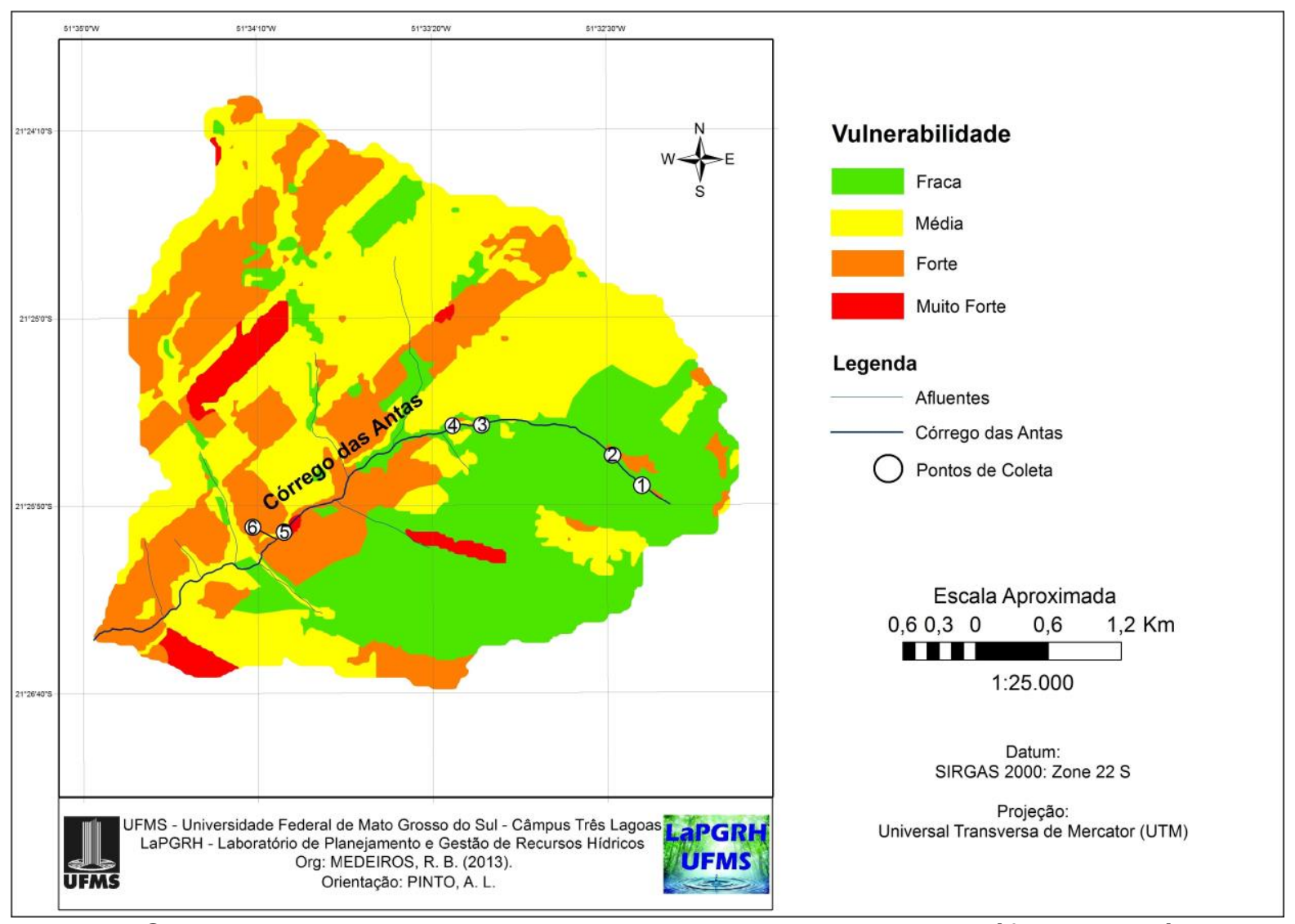

Figura 2: Carta de vulnerabilidade ambiental da bacia hidrográfica do córrego das Antas/SP.

Tabela 7: Vulnerabilidade e Qualidade e Enquadramento das Águas da bacia do Córrego das Antas.

\begin{tabular}{|c|c|c|c|c|c|c|c|c|c|c|}
\hline $\begin{array}{c}\text { Classe de } \\
\text { Vulnerbilidade }\end{array}$ & \multicolumn{2}{|c|}{ Pontos } & Hora & $\begin{array}{l}\text { C. E. } \\
\text { (um) }\end{array}$ & $\begin{array}{l}\text { O. D. } \\
(\mathrm{mg} / \mathrm{l})\end{array}$ & $\begin{array}{l}\text { Temp } \\
. \text { Ar } \\
\left({ }^{\circ} \mathrm{C}\right)\end{array}$ & $\begin{array}{l}\text { Temp } \\
. \mathrm{H} 2 \mathrm{O} \\
\left({ }^{\circ} \mathrm{C}\right)\end{array}$ & $\mathrm{Ph}$ & $\begin{array}{c}\text { Turbidez } \\
\text { NTU }\end{array}$ & $\begin{array}{l}\text { Classe de } \\
\text { Enquadra- } \\
\text { Mento }\end{array}$ \\
\hline Fraca & \multirow{2}{*}{$\begin{array}{l}\text { Alto } \\
\text { Curso }\end{array}$} & \multirow{2}{*}{$\begin{array}{l}1 \\
2\end{array}$} & $10: 15$ & 100,00 & 9,80 & 22,75 & 22,72 & 6,91 & 133,00 & IV \\
\hline Forte & & & $10: 40$ & 92,00 & 5,60 & 22,53 & 22,14 & 9,05 & 37,00 & IV \\
\hline Fraca & Médio & 3 & $11: 40$ & 114,00 & 8,10 & 23,37 & 22,51 & 6,68 & 35,50 & III \\
\hline Média & Curso & 4 & $12: 00$ & 113,00 & 8,30 & 23,46 & 24,33 & 6,64 & 12,30 & III \\
\hline Muito Forte & Baixo & 5 & $14: 10$ & 88,00 & 6,10 & 29,45 & 25,06 & 6,46 & 14,50 & II \\
\hline Forte & Curso & 6 & $14: 30$ & 87,00 & 7,00 & 27,40 & 24,75 & 6,42 & 19,90 & II \\
\hline Média Bacia & - & & - & 99,00 & 7,48 & - & - & 7,02 & 42,03 & IIII \\
\hline
\end{tabular}

Org: MEDEIROS (2013).

Orientação: PINTO, A. L. 
Na bacia do córrego das Antas não obteve a categoria de vulnerabilidade Muito Fraca, que segundo Medina et al. (2000) esta classe se caracteriza por possuir, erosão laminar desenvolvida pelo escoamento difuso das águas pluviais tem pouca competência devido ao fraco ou inexistente gradiente topográfico. São áreas de baixada ou planícies de acumulação de sedimentos, como as planícies fluviais, marinhas e manguezais.

A categoria Fraca ficou na segunda classe de maior ocorrência, apenas inferior a Média, ocorrendo em 29,35\% da bacia, sendo que abrangeu o ponto 1, do monitoramento, alto curso da bacia, enquadrada na classe IV de qualidade das águas, próximo a nascente, envolto de mata, relativamente fechada, com aproximadamente 4 anos de recomposição pela CESP. Nota-se, porém, a existência de escoamento superficial e a deposição de sólidos dissolvidos ferrosos, que elevam a turbidez da água e o seu posicionamento na classe IV.

Ainda integrante na classe de vulnerabilidade, abrangeu-se também, o ponto 3 , sendo ela classificada como classe III de qualidade das águas, mesmo estando em uma classe fraca de vulnerabilidade, se encontra em uma área de várzea, com também acumulo de sólidos ferrosos dissolvidos, originados de sedimentos da formação Vale do Rio do Peixe, que provocam o aumento da condutividade elétrica - CE.

A categoria fraca é caracterizada pela fraca erosão laminar, sem evidência erosiva, com infiltração das águas, ou moderada, com ligeiras evidências de sinais incipientes de erosão laminar por escoamento difuso ou semiconcentrado, (MEDINA, et. al, 2000).

A categoria de vulnerabilidade Média foi predominante na bacia, onde representou $39,41 \%$ da área total, esta área abrangeu o ponto 4 , no médio curso, que mesmo sendo uma área mais vulnerável, tem sua mata ciliar bem formada e fechada, recomposta pela CESP a mais de 6 anos, que promove a elevação da vazão e da concentração de oxigênio dissolvido - OD, contudo a sua condutividade elétrica é elevada, devido também as concentrações de sólidos ferrosos dissolvidos, a enquadrando na classe IV.

Esta classe de vulnerabilidade abrange as áreas de relevo colinoso - colinas residuais e colinas tabulares - com interflúvios tabulares sobre os tabuleiros costeiros e parte da superfície pré-litorânea e superfícies dos tabuleiros mais dissecadas com maior densidade de drenagem. Esta classe de vulnerabilidade relaciona-se a uma instabilidade morfodinâmica caracterizada por erosão laminar fraca a média responsável pela remoção 
parcial dos horizontes superficiais dos solos e pela existência de sulcos erosivos localizados pelo escoamento semiconcentrado. Ocorre também a formação incipiente de terracetes de pisoteio, que em estágio mais avançado podem evoluir para sulcos erosivos. Esses processos ocorrem mais nas superfícies das vertentes dos vales com aprofundamento de drenagem variando de 20 a 60m (amplitudes locais de relevo), (MEDINA, et. al.; 2000).

A classe de vulnerabilidade Forte se apresentou em uma área de $5,16 \mathrm{~km}^{2}$ ou $27,64 \%$ da área total da bacia, onde fica localizado o ponto 2 que foi enquadrado como classe IV. A vulnerabilidade forte ao predomínio das pastagens mal plantadas e manejadas, que aumentam o escoamento superficial, reduz o oxigênio dissolvido na água, limitando seu uso à apenas abastecimento para consumo humano, após tratamento convencional ou avançado. O elevado $\mathrm{pH}$, o mais elevado da bacia, acima o limite máximo permitido, que é de 6 a 9, foi a principal razão de seu enquadramento na classe IV

Já o ponto 6 que também se encontrou em uma área de vulnerabilidade forte, se enquadrou na classe II, mesmo estando em local de declividade elevada, em vale encaixado em forma de $\mathrm{V}$ e com mata ciliar plantada a menos de 7 meses, a densa vegetação de gramíneas existente no canal auxilia, conjuntamente com a velocidade de fluxo da água, na sua oxigenação e consecutiva melhoria da qualidade. A principal variável que promove o seu enquadramento na classe II, foi a condutividade elétrica.

Estes terrenos são bastante suscetíveis à erosão, a vulnerabilidade forte evidenciase pela remoção parcial dos horizontes superficiais dos solos, presença localizada de sulcos, ravinas e terracetes de pisoteio, principalmente quando o pastoreio é intenso. $\mathrm{O}$ escoamento superficial pluvial é difuso, semiconcentrado e por vezes, concentrado em canais, significando, nesse caso, uma distribuição bastante diferenciada da energia desses fluxos na superfície. Os processos erosivos são tanto mais intensos quanto menor for à proteção dada pela cobertura vegetal ao horizonte superficial do solo, (MEDINA, et. al., 2000).

A categoria muito forte foi encontrada principalmente em áreas de solo nu, onde o escoamento superficial é muito alto aliado ao solo exposto que é levado até as áreas mais baixas, fundos de vale e os recursos hídricos, tornando assim uma área muito vulnerável, e abrangeu $3,60 \%$ do total da bacia. Onde está inserido o ponto 5 de coleta de água, que 
é caracterizado pelo córrego correr encaixado nas rochas, onde o declive é acentuado e não existe mata ciliar, porém a grande velocidade de fluxo da água, ao passar sobre os matacões de arenitos dispersos ao longo do canal, oxigena a água, contribuindo para ser classificada como classe II de qualidade. A condutividade elétrica, derivada do intemperismo químico dos arenitos rico em ferro, foi a principal razão de seu enquadramento nessa classe.

Este tipo de local de vulnerabilidade muito forte é corresponde às áreas com declividades acentuadas nos bordos dos tabuleiros costeiros, ao longo das vertentes dos vales mais profundamente dissecados e nas cabeceiras de drenagem, ocorrem solos com horizontes superficiais degradados, grandes concentrações de terracetes de pisoteio, sulcos erosivos, ravinas e cicatrizes de deslizamento, (MEDINA, et. al., 2000).

\section{CONCLUSÃO}

A Analise das áreas vulneráveis e potencialmente propensas a erosões, de uma determinada bacia, constitui em importante ferramenta, pois percebe-se que as unidades morfoestruturais possuem propriedades comuns, sendo que o estado de cada unidade é controlado, condicionado ou dependente do estado das demais unidades, que compõem a paisagem (MMA, 2001.14).

$\mathrm{Na}$ bacia do córrego das Antas, após o levantamento dos dados necessários para a elaboração deste estudo, percebe-se o predomínio da formação arenítica do Vale do Rio do Peixe, recobertos por Argissolo Vermelho/Amarelo, em declividade suave, de $0-6 \%$. Utilizados sobre tudo pelas pastagens, onde $52,47 \%$ da área total obteve vulnerabilidade média, em $39,41 \%$ de toda a área da bacia, o que mostra que é uma área de mediana vulnerável, que refletiram em manejos diferenciados da terra, que culminaram no enquadramento médio da bacia na classe III. Que possui as seguintes limitações de uso da água: abastecimento para consumo humano, após tratamento convencional ou avançado, à irrigação de culturas arbóreas, cerealíferas e forrageiras, à pesca amadora, à recreação de contato secundário e à dessedentação de animais.

Conclui-se que a qualidade das águas da bacia mais se desqualificou devido a processos erosivos que carreiam sedimentos ao canal fluvial, que elevam a turbidez e/ou condutividade elétrica, sendo solucionados pelo ordenamento do uso, ocupação e manejo 
da terra. Baseados em técnicas corretas de plantio e sobre tudo de manejo, do solo, das estradas, das plantações e das criações, que dificultem a ação da água corrente.

\section{REFERÊNCIAS}

BRASIL Conselho Nacional do Meio Ambiente - CONAMA Resolução 357/2005, Enquadramento dos Corpos Hídricos Superficiais no Brasil.. Governo Federal, Brasília. Publicada no DOU n 53, de 18 de março de 2005, Seção 1, páginas 58-63.

CHRISTOFOLETTI, A. Geomorfologia. 2ª edição. São Paulo: Edgard Blucher, 1980. $188 p$.

CPRM - Serviço Geológico do Brasil. GeoBank. Disponível em: http://www.cprm.gov.br/. Acesso em: 12 de Jun. 2013.

CREPANI, E.; MEDEIROS, J.S. de; HERNANDEZ FILHO, P.; FLORENZANO, T.G.; DUARTE, V.; BARBOSA C.C.F. - Sensoriamento Remoto e Geoprocessamento Aplicados ao Zoneamento Ecológico Econômico e ao Ordenamento Territorial. São José dos Campos, Junho de 2001 (INPE 8454-RPQ/722).

EMBRAPA. Banco de Dados Climáticos do Brasil. Disponível em: <http://www.bdclima.cnpm.embrapa.br/resultados/index.php?UF=sp> Acesso em: 08 de Jul; 2013.

EMBRAPA. Centro Nacional de Pesquisa de Solos. Sistema Brasileiro de Classificação de Solos. Rio de Janeiro, 1999. 412 p.

FERNANDES L.A.; GIANNINI P.C.F.; GÓES A.M. 2003. Araçatuba Formation: palustrine deposits from the initial sedimentation phase of the Bauru Basin. Anais..., Academia Brasileira de Ciências, Rio de Janeiro, 75(2):173-187.

IBGE. Instituto Brasileiro de Geografia e Estatística. Manual de uso e ocupação da terra. Manuais Técnicos em Geociências. Brasil número 7. Brasília, 2006. 91p.

LEPSCH, I. F. Formação e Conservação dos solos. São Paulo: Ofícina de Textos, 2002,178p.

LIMA, L. C.; MORAIS, J. O.; SOUZA, M. J. N. Compartimentação territorial e gestão regional do Ceará. Fortaleza: UNECE, 2000, 268p.

MATHEUS, C. E. et al. BICRHEA - Centro de Recursos Hídricos e Ecologia Aplicada da USP. USP. São Carlos, 1995: 62p. 


\section{Then Fórum Ambiental \\ da Alta Paulista

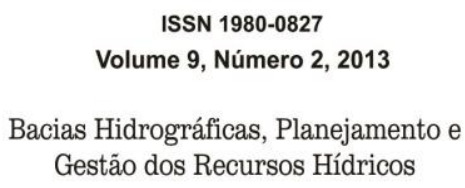

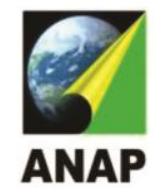

MEDINA, A. I. M (Org). Projeto Porto Seguro - Santa Cruz Cabrális: Geomorfologia, Avaliação da Vulnerabilidade à Erosão e Diagnóstico Geoambiental. Salvador: CPRM/SUREG/SA, 2000. 87p.

MMA. Programa Zoneamento Ecológico-Econômico: diretrizes metodológicas para o zoneamento ecológico-econômico do Brasil. Ministério do Meio Ambiente Secretaria de Políticas para o Desenvolvimento Sustentável. Brasília - DF, 2001.

OLIVEIRA, A.M.M.; PINTO, S.A.F.; LOMBARDI NETO, F. Caracterização de indicadores da erosão do solo em bacias hidrográficas com o suporte de geotecnologias e modelo predictivo. Estudos Geográficos, Rio Claro, v.5, p.63-86, 2007.

PINTO, A. L. Saneamento Básico e suas Implicações na Qualidade das Águas Subterrâneas da Cidade de Anastácio (MS). 1998. 175p. Tese (Doutorado e Geociências) - Universidade Estadual Paulista/Instituto de Geociências e Ciências Exatas, Rio Claro, 1998.

REBOUÇAS, A. da C. Água doce no mundo e no Brasil. In: REBOUÇAS, A. da C.; BRAGA, B. e TUNDISI, J. G. (Orgs.). Águas doces no Brasil: capital ecológico, uso e conservação. São Paulo: Escrituras Editora, 2002.

ROSS, J. L. S. Análise Empírica da Fragilidade dos Ambientes Naturais e Antropizados. Revista do Departamento de Geografia. São Paulo: FFLCH-USP, n8, 1994.

SALLUN A. E. M; CHRISTOFOLETTI S. R., SALLUN FILHO, W. AMARAL, R.; AZEVEDO SOBRINHO, J. M.. Argilominerais da Aloformação Paranavaí (SP, PR E MS) São Paulo, UNESP, Geociências, v. 29, n. 3, p. 311-319, 2010.

TRICART, J. Ecodinâmica. Rio de Janeiro. IBGE/SUPREN, 1977. 91p. 